\title{
Expression of Concern \\ Expression of Concern Regarding Jensen (2002), "Value Maximization, Stakeholder Theory, and the Corporate Objective Function"
}

$B$ usiness Ethics Quarterly (BEQ) is issuing this expression of concern to alert readers to concerns about redundant publication of an article by Michael C. Jensen, "Value Maximization, Stakeholder Theory, and the Corporate Objective Function," which appeared in BEQ in 2002.

Redundant publication is defined by the Committee on Publication Ethics (COPE) as occurring "when a published work (or substantial sections from a published work) is/are published more than once (in the same or another language) without adequate acknowledgment of the source/cross-referencing/justification." ${ }^{1}$ A concern about redundant publication of this article came to the attention of BEQ's editors in 2017 in correspondence from a reader.

BEQ and its publisher Cambridge University Press are members of COPE; we adhere to COPE principles and follow its recommended procedures when issues of possible research or publication misconduct arise. In the present circumstance, we followed the procedures suggested by COPE when redundancy in an already published manuscript is suspected. ${ }^{2}$ To carry out the inquiry and assist with reaching an outcome, we formed an ad hoc panel comprised of BEQ's editor in chief and two associate editors.

Our inquiry finds that a close-to-identical version of the article we published (Jensen 2002), carrying the same title, appeared in the journal European Financial Management (Jensen 2001a), and a non-identical version with a substantial amount of overlapping content, also carrying the same title, appeared in the Journal of Applied Corporate Finance (Jensen 2001b). ${ }^{3}$ Neither of these versions are acknowledged or cited in the published BEQ article. The BEQ article includes an author note (Jensen 2002, 254) indicating that an earlier version of the paper appeared in an edited volume published by Harvard Business School Press (Beer and Norhia 2000). A similar note regarding prior publication in the Beer and Norhia volume appears in each of the other two journal versions (Jensen 2001a and Jensen 2001b), but none of the journal versions mentions or acknowledges any of the other journal versions.

It is relevant to understand the circumstance under which the version of the Jensen article that appeared in BEQ came to be published. Although the issue of BEQ in which it appeared (vol. 12, no. 2) was not identified in the table of contents as a special issue, the articles comprising the issue were a collated "symposium" (quoting from the introductory and lead article; Donaldson 2002, 107) on stakeholder theory. Recollections and extant records of BEQ's editors, as well as of the editors of the 
two finance journals (whom we contacted), reveal the following. First, the Jensen article was never presented or framed as a wholly original contribution for BEQ. The guest editor who collated the symposium learned of the Jensen piece at a conference, and both he and the main editor knew before accepting it for publication in BEQ that a version had appeared in the Beer and Norhia volume. Second, although the Jensen articles appeared in print in the two finance journals before the issue of BEQ containing it was printed, the article was under consideration at BEQ before it appeared in print in either of the other two journals. Third, while a precise sequence of editorial activity is hard to pin down given the passage of time and imperfect records and memories, it appears that editors of all three journals were more or less simultaneously vetting versions of the Jensen article.

In keeping with COPE guidelines for inquiries of this sort, we contacted the author, Jensen, who informs us that he has no recollections of the circumstances, assumes that the article was solicited by BEQ for publication, and surmises that he was aware of no conflict at the time. The author note in the BEQ article (Jensen 2002,254 ) that mentions the publication of a prior version in an edited volume also states that the article is published in BEQ "under license" from the author, who "retains copyright."

At the time of publication of the Jensen article in BEQ the journal did have a policy regarding originality of contribution which read: "BEQ will not consider a manuscript that is currently under consideration elsewhere or has been published previously, except for special circumstances." The editor of BEQ at the time acknowledges that the author of an invited paper which was known to the editors to have been previously published (in the edited volume) might reasonably not have consulted BEQ's information for contributors containing the policy just quoted. While that doesn't excuse an author from complying with a journal's submission policies, it does present an explanation that some might find reasonable. We also note that developments in online publishing platforms along with evolving norms of and heightened attention to publication ethics make it plausible to view these circumstances in somewhat different light than might have been the case in the early 2000s.

If an author of his or her own accord knowingly submits an article for publication to two different journals having policies against redundant publication without proper cross-acknowledgement, a breach of publication ethics for which the author is responsible will have occurred, and retraction of the article is, according to COPE, an outcome that a journal should entertain. That, however, is not what happened here, given that it appears that the article was invited by editors (BEQs' and the other journals'), knowing that it had been previously published somewhere, and that the author took the step of expressly reserving copyright.

Nonetheless, it is matter of concern that virtually identical versions of the same article, and a third version that is substantially overlapping, appeared in journals having non-redundancy policies, with none of these articles cross-citing or crossacknowledging the others. Our concern here of course is for BEQ, not for the other journals involved, whose own editors can act or not as they wish. But we do feel a responsibility not just to this journal's readers and stakeholders, but also to 
the scholarly community at large, to express our concern for the record that this redundant publication without acknowledgement was inappropriate, and to ensure that future scholars who come upon this article in BEQ's archives will be aware that it occurred.

Bruce Barry

Editor in Chief

\section{NOTES}

1. Committee on Publication Ethics, "Redundant Publication." https://publicationethics.org/category/ keywords/redundant-publication.

2. Committee on Publication Ethics, "Suspected Redundant Publication in a Published Manuscript." https://publicationethics.org/resources/flowcharts/suspected-redundant-publication-published-manuscript.

3. The Journal of Applied Corporate Finance reprinted its version of the article in a 2010 special issue titled "Honoring Michael Jensen" (vol. 22, no. 1).

\section{REFERENCES}

Beer, Michael, and Nitin Nohria, eds. 2000. Breaking the Code of Change. Boston: Harvard Business School Press.

Donaldson, T. 2002. "The Stakeholder Revolution and the Clarkson Principles.” Business Ethics Quarterly 12 (2): 107-111.

Jensen, Michael C. 2001a. "Value Maximisation, Stakeholder Theory, and the Corporate Objective Function.” European Financial Management 7 (3): 297-317.

. 2001b. "Value Maximization, Stakeholder Theory, and the Corporate Objective Function." Journal of Applied Corporate Finance 14 (3): 8-21.

- 2002. "Value Maximization, Stakeholder Theory, and the Corporate Objective Function." Business Ethics Quarterly 12 (2): 235-256. 